\title{
Challenges and Opportunities for the community of Food Sciences to contribute Towards a Society of Healthier Consumers and a Better World
}

\author{
HARRis N. LAZARIDES * \\ Department of Food Science and Technology, Faculty of Agriculture, Aristotle University of Thessaloniki, Box \\ 235, 541 24, Hellas \\ TEL: +30-2310-991633 \\ FAX: $+30-2310-991632$ \\ *Lazaride@agro.auth.gr
}

Received: 9 September 2011; Published online: 18 April 2012

\begin{abstract}
Despite the tremendous scientific and technological achievements in the production of food, human well-being has not been served to a satisfactory extent. Millions of people are literally killing themselves by excessive eating or wrong use of food, leading to obesity and nutrition-related diseases. At the same time millions of people continue to suffer from lack of food, leading to starvation, malnutrition and death, often before reaching adult age. Parallel to striving for better-safer-healthier food, the community of Food Sciences is faced with the challenge to help educate the average consumer on how to select, handle, store and use food for safe and healthy eating. The need to reshape and reform public education to better serve this task is obvious. What is also obvious is the need for medical professionals to recognize healthy eating (and exercise) as the most valuable tool in preventive medical care. This perspective will concentrate on challenges and opportunities for Food Scientists/Engineers: to contribute towards a society of well-informed, self-protected, active and considerate citizens; to support public (food-related) education and actively participate in the fight against obesity and nutrition-related diseases; to intervene in decision making bodies and underline the importance of education on nutrition and food; to invent avenues and possibilities to contribute to the fight against world hunger; and all in all, to contribute towards a healthier world, a world that will not be split between hunger and obesity.
\end{abstract}

Keywords: food and well-being, consumer education, world hunger, nutrition-related diseases, starvation, food education

\section{Introduction}

Food has always been the main concern of humans throughout the history of mankind. Our far ancestors struggled for food and shelter and this is, alas, still the case for millions of people these days.

Thanks to the valuable input of thousands of dedicated researchers, Agricultural and Food Sciences have made (and keep making) tremendous progress in several rather challenging fields re- garding the production, processing and handling of food. Despite this progress, however, in one way or another food remains the number one problem all over the world. While millions of people in developing countries and a growing percentage of people in developed countries starve to death, a dramatically increasing proportion of people in developed countries literally kill themselves through over-consumption or incorrect use of food, leading to obesity and a long series of food-related diseases (Simopoulos, 1985). 
Our civilization is proud of great scientific and technological achievements; yet, we have become used to living comfortably with such devastating problems, such as world hunger or even the obesity epidemic! While we can manage incredibly complex and challenging problems, we cannot manage providing food and clean water for our fellow citizens on this planet. We also fail to teach our children how to live on a healthy diet and gain their well-being.

This situation also questions the social benefit of great scientific achievements by our Food Science community. If we are doing so well with production, processing and handling of food, why arent we serving equally well human well-being? Why do so many people keep suffering because of food? What exactly causes and sustains the world hunger problem? Where is our real input as food scientists and fellow citizens? What are the main causes of wrong eating habits leading to the obesity epidemic? What is the share of responsibility for each and every stakeholder in this problem? What is our share of responsibility and how can we better serve the fight against world food problems? Can we all join forces to work for a new world, where food is not a problem leading to disease or death, but a holy gift nurturing life? Both the right to food and access to the right food must become fundamental priorities of our social service as food scientists.

\section{Food problems in developing countries}

It is well known and, alas, well accepted that large parts of populations in developing countries keep suffering for long periods of time from hunger, malnutrition and lack of potable water. According to a FAO report (FAO, 2002), it is estimated that 1.02 billion people out of 6.8 billion of the present world population are suffering from hunger; that is $15 \%$ of the world population! Compared to the 2006 estimate of 854 million hungry, this is a tremendous increase within a very short period of time and an alarm for negative developments to come.

What really causes and sustains the world hunger problem? Is it lack of adequate food?

The answer is negative. According to Amartya
Sen, the 1998 Nobel laureate in Economics, The world supply of food is sufficient to feed the world population; simply food is not where needed, when it is needed. According to FAO data (FAO, 2009), world agriculture produces $17 \%$ more calories per person today than it did 30 years ago, despite a $70 \%$ population increase. This is enough to provide everyone in the world with at least $2,720 \mathrm{kcal}$ per person per day. What is the problem then?

- Is it questionable care by world leaders?

- Is it low social awareness and lack of fellowship?

- Is it low sensitivity of modern societies?

- Is it low respect for human rights?

It seems that all the above are true to a certain extent. It is finally and simply lack of adequate care! If the world leaders really cared, they would not use shortage of food as a means to manipulate and control developing countries. If the world leaders really cared, they would not buy out the pollution rights of poor countries (Kyoto agreement) for food. If the world leaders really cared, they would not buy out their land and waters to dump nuclear waste compensating for environmental damage with supplies of food. They would not allow (or even encourage and facilitate) the crime of land grabbing to happen; vast areas of Africa are sold to multinationals to produce food for export, leaving local people without vital land resources to produce their own food (White \& Dasgupta, 2010).

All in all, if the developed countries really cared, they would manage to bring food where it is needed, when it is needed as a short term (immediate) response to a famine; thus they would manage to minimize the impact of famines. In the long run, they would systematically, constantly and persistently help developing countries acquire their own capacity to produce food; to become self sufficient and independent, as a long term (radical) response. What can we, as food scientists, do to help?

Among other possibilities, agronomists could work on preserving local and/or developing new plant varieties that are suitable for extreme soil 
Challenges and Opportunities for the Community of Food Sciences $\mid 103$

and weather conditions, against their threatened displacement by Genetically Modified Organism (GMO) varieties. They can also work on water preservation techniques and satellite surveillance of food crops in problematic areas to predict and prevent famines. Training of local agronomists and help to develop the required infrastructures are among fundamental prerequisites to liberate productive forces and generate extensive, rural development. IT and distant learning tools can be used for low-cost teaching and technology transfer.

Strict legislation, sensible policies and effective strategies are also needed to protect vital land that is used to feed poor people in developing countries from land grabbing by multinational ventures. This is especially urgent as the pressure for biofuel production is increasingly driving towards acquisition of new lands.

Food scientists/engineers could work on developing formulas and processes for nutraceuticaltype products, to be used as complete, balanced meals (i.e. reconstituted drinks, stable dry meals). They can also provide distant teaching services on fundamentals of food preservation, considering lack of electricity and relevant storage or preservation facilities in developing countries. It is well known that large volumes of food produced in these countries do not reach the consumer table (they spoil) due to transportation, storage and preservation problems.

An open forum to discuss and contribute towards eradication of the hunger problem could also be a valuable tool to mobilize the global Agriculture/Food Science community. To this effect, IUFoST (International Union of Food Science and Technology) has constituted a Task Force on Food Security, under the leadership of IUFoST Past President, Prof Walter Spiess, which includes two World Food Prize Laureates, International Academy Fellows M.S. Swaminathan from India, and Philip Nelson from the USA.

Finally, systematic work is needed on raising public awareness, stressing societal and corporate responsibility. All in all, a long-term approach should constantly concentrate on ways to help developing countries develop their own production capacity and food sovereignty rather than offering them food during periods of famine.

\section{Food problems in developed countries}

The following food-related problems have to be faced in developed countries:

- Obesity and diet-related diseases

- Food safety problems (food crises)

- Mishandling of food by the consumer

- Oligopoly in food market control (globalization)

- Low access to food due to increasing poverty (read hunger)

During the last decades, demographic and socio-economic changes have resulted in dramatic changes of life-style, which include drastic changes in eating behavior. The every-day family table has been forgotten to a large extent and fast food or eating out has been taking up a growing part of our eating habits. Traditional family dishes tend to belong in the past as they have been replaced by bland, universal, convenience dishes. The so-called western style of eating with large servings results in high intake of calories, sugar, salt, animal fat, trans-fatty acids and cholesterol. All these have a negative impact on health, leading to a number of western-type diseases, such as obesity, diabetes, hypertension, cardiovascular diseases (CVD), anemia, cancer, etc. (Simopoulos, 1985).

It is rather ironic that, while people in some parts of our planet die because of lack of food, others living in areas of affluence die because they consume too much food or because they fail to choose the right food and follow a balanced diet. It is also interesting that obesity is prevalent among poor population groups. According to a relevant study, food insecurity and obesity were found to be positively associated in Mexico City schoolchildren (Ortiz-Hernandez, Nayeli Acosta-Gutierrez, Nunez-Perez, Peralta-Fonseca, \& Ruiz-Gomez, 2007). This is probably due to easier access to unhealthy (high fat and high calorie) food of lower cost. Additionally, lack of 
food and nutrition education plays a significant role in making the wrong food choices.

What is obesity really? In fact, obesity is a modern, epidemic, devastating global disease; therefore the term globesity has recently been used .

The new IASO/IOTF analysis (IASO, 2010) estimates that approximately 1.0 billion adults are currently overweight (BMI 25-29.9 Kg/m²), and a further 475 million are obese. Globally, IASO/IOTF estimate that up to 200 million school aged children are either overweight or obese, of which 40-50 million are classified as obese. In the European Union 27 member states, approximately $60 \%$ of adults and over $20 \%$ of school-age children are overweight or obese. This equates to around 260 million adults and over 12 million children being either overweight or obese.

It is rather surprising to consider peoples responses to a serious health problem like obesity. Despite the obvious need for medical help and professional treatment, a lot of people deal with obesity in rather superficial, irresponsible and empirical ways, that is:

- Without professional consultation

- Without patience to safely lose weight under the guidance of a specialist

- With the use of dangerous diet schemes, including absolute withdrawal from eating for long periods of time (read starvation)

- With easy belief in fake promises (by slimming centers), making themselves believe in easy, miracle solutions

What are the real causes of development of such an unhealthy and dangerous style of eating? Among other reasons, wrong eating habits may be due to:

- Lack of nutrition and food education

- Lack of time for preparing a healthy meal; seeking convenience and easy solutions (fast food, TV dinners); more often than ever people eat out and their diet largely depends on ready meal providers, such as fast food or food companies offering precooked food (i.e. heat and serve meals)
- Seeking entertainment and fun instead of nurturing to sustain (junk food, snacks, soft drinks, alcohol)

- Consumerism (over-consumption, wasting)

- Deterioration of the family fabric leading to abolishment of such institutions, as the family table (crisis of values)

- Devaluation of the importance of tradition, leading to lack of protection and eventual loss of valuable, healthy traditional dishes

- Fashion and style. Young people are especially vulnerable to media advertisements directing not only their food choices and style of eating, but also the way they should look (i.e. thin like models), which often leads to serious health complications (i.e. anorexia nervosa)

How can we correct our eating habits? This is a rather difficult and long-term objective that needs coordinated actions. Among other measures we need to work on the following tasks:

- Improve Food and Nutrition Education at all school levels (nursery, primary, secondary); school canteens may present a serious obstacle, as they usually offer a lot of junk food and soft drinks

- Introduce Food and Well-being courses at University level for non-food science majors

- Improve public awareness of the value of healthy eating and exercise (radio, TV, media)

- Improve preventive medical care with better training of medical doctors on nutrition and health (prevention vs. cure)

- Carry out clinical nutrition studies to recognize and prevent the development of unhealthy and dangerous nutritional (eating) patterns

- Establish clear nutrition policy (State, Federal, European) and take effective measures to implement it 
- Apply easy to read, understandable nutritional labeling, not only on packaged food but also on restaurant served meals

- Legislate and enforce corporate (producer) responsibility.

In fact corporate responsibility is a very important issue to be addressed. A recent study proved that companies are failing to live up to their pledges to reduce sugar, salt, trans-fat, cholesterol, serving sizes and calories. Researchers at City University (UK) reviewed the companies' policies on nutrition, research and development, marketing, labelling and other criteria relating to health. The world's top 25 food companies have not taken significant action to improve diets despite their claims (Lawrence, 2006).

Makers, retailers and restaurant chains were all accused. According to Tim Lang, one of the authors of the report The Food Industry, Diet, Physical Activity and Health: a review of reported commitments and practice of 25 of the worlds largest food companies (Lang, Rayner, \& Kaelin, 2006),

"...Their performance is by and large pathetic... The companies that appear to be doing the most are the ones under intense pressure because their product ranges are the unhealthiest, but there is a whiff of desperation about what they are doing rather than long-term commitment to better food....

In short, the following responses were recorded in the above report:

- Five out of 25 companies reported acting on sugar

- Four out of 25 reported acting on fat

- Eight out of 25 reported acting on trans-fats

- Ten out of 25 reported acting on salt

- Two out of 25 reported acting on portion sizes

- Four out of 25 had stated policies on food advertising
In light of globalization and global food market control, food safety has acquired new dimensions. Intensification of production techniques has helped increase productivity and decrease production costs. At the same time this has taken place at an enormous cost in terms of food safety (Sassenrath et al., 2008). During the last two decades the world has been faced with a number of food crises including BSE (Bovine Spongiform Encephalopathy or mad cow disease), dioxins, acrylamide, growth hormones and antibiotic resistance, all related to newly developed, highly intensified and unsustainable production methods. Food from GMOs has raised enormous disputes with respect to safety, environmental impact, biodiversity, bioethics, food market control and consumer rights regarding free, well-informed choice of food (read obligatory labeling).

As global food market control has been passing through fewer hands, with questionable respect to human values or the environment, there has been a dangerous shift in production priorities. Instead of focusing in production of food with high safety, satisfactory quality and acceptable (reasonable) cost, the new production priorities focus on low cost and acceptable quality, resulting in questionable safety.

It is time to stop and reconsider our production practices, paying more attention to production ethics. In order to secure safe food, we need to re-orient production schemes to sustainable methods, moving away from intensificationinduced food crises). At the consumer level we need to help improve awareness of real values (important attributes) in food (nutrition, quality, safety). We also need to support the consumer movement for better protection of rights regarding:

- Consumer education

- Access to safe food for all

- Free, well-informed choice (i.e obligatory labeling of GM food) through informative (not misleading) and adequate food labeling.

Consumer education is a basic consumer right and an absolute pre-requisite for consumer responsibility with respect to making the right 
choice and safe handling of food. Mishandling of food by the consumer will easily cancel every effort and achievement of the Food Industry with respect to quality, nutritional value and safety; thus canceling the positive impact of valuable achievements in food research (that is, the impact of our own work!). As an example, the following scenarios were tested (using Monte Carlo Simulation) to identify effective actions for improvement of pasteurized milk shelf life in the Hellenic chill chain (Koutsoumanis, Pavlis, Nychas, \& Xanthiakos, 2010):

1. Improvement of initial microbiological quality (reduce mean level of Bacillus by 1 log $\mathrm{cfu} / \mathrm{ml})$

2. Improvement of retail temperature conditions (reduce mean retail storage temperature by $2^{\circ} \mathrm{C}$ )

3. Excluding door shelf from domestic storage of milk

4. Improvement of domestic refrigerator temperature conditions (reduce mean domestic storage temperature by $2^{\circ} \mathrm{C}$ )

An importance analysis of the above factors affecting milk spoilage showed that better temperature control of domestic refrigerators is the most effective action for extending shelf life, compared to better control of hygienic conditions during production or better temperature control at retail. In fact, a reduction of $2^{\circ} \mathrm{C}$ in the mean temperature value of domestic refrigerators increased the $\%$ of cartons with shelf life longer than 8 days to $95 \%$ (up from $72 \%$ ) and eliminated cartons with shelf life less than 5 days.

Parallel to striving for better-safer-healthier food, the community of Food Sciences is faced with the challenge to help educate the average consumer on how to select, handle, store and use food for safe and healthy eating. The need to reshape and reform public education to better serve this task is obvious. What is also obvious is the need for medical professionals to recognize healthy eating (and exercise) as the most valuable tool in preventive medical care. Unfortunately, the response of the medical community to this need has been rather slow and far from systematic.
Consumer education has been recognized as a main task for the ISEKI Food Thematic Network. One of its main objectives has been to establish communication with the general public and consumers. Within the first version of ISEKI Food, Working Group 3 worked on Food Science/Engineering and the general public. Later on, within ISEKI Food 2, Working Group 3 worked on developing teaching materials and methods in the field of Food Studies, including material for the general public. The ISEKI Food Association (IFA) (www.iseki-food.net) has also been established as a sustainable continuation of the ISEKI Food Thematic Network. Among the first tasks to be accomplished within the framework of IFA has been a database of Food Info for the average consumer in $14 \mathrm{EU}$ languages (see Food-Info). Last but not least is the problem of food market control as a result of market globalization.

Today, the top 10 companies control half of the worlds commercial seed sales. With control of seeds and agricultural research held in fewer hands, the worlds food supply is increasingly vulnerable to the whims of market maneuvers. Corporations make decisions to support the bottom line and increase shareholder returns not to insure food security ( Food Democracy Blog).

According to Konefal, Mascarenhas, and Hatanaka (2005), the global, political-economic, capitalist transformation globalization is a transition from a Fordist regime to a regime of flexible accumulation. They also argue that the standard making process of this new regulatory regime is increasingly moving from the front stage where it is open to public debate and democratic decisionmaking bodies to the backstage where it is dominated by large supermarket procurement offices. Finally, they assert that transnational supermarket chains are increasingly controlling what food is grown where, how, and by whom.

The following conditions describe the environment within which the world food market has been developing:

- Powerful world organizations (WTO, FAO, Codex Alimentarius)

- Lack of transparency in decision making processes 
Challenges and Opportunities for the Community of Food Sciences $\mid 107$

- World citizens are simply watching the drastic changes shaping their future

- Food market control is passing into fewer hands; hands with low respect for human needs, consumer rights or the environment (e.g. GMOs)

- Gradual and continuous shift of power from SMEs to large multinationals; from poor to rich countries

- Hunger is now a growing concern EVEN in rich countries

\section{Conclusion}

A large proportion of the world population is suffering from food in one way or other. Developing countries are suffering from hunger and malnutrition, thus struggling for their right to food. On the other hand, developed countries are faced with obesity and nutrition-related diseases, thus struggling for use of the right food; they are also faced with a growing concern for hunger of their lower income classes. Obesity is a major health problem of modern societies with dimensions of an epidemic disease. Consumer education is absolutely needed to promote food quality/safety and healthy eating. School teachers need thorough training, effective teaching tools and proper coursework design to efficiently teach todays children and tomorrows parents how to choose high quality/safe food and how to live on a healthy diet. The community of Food Sciences should urgently develop such tools. Corporate responsibility is a major issue in combating obesity and food related diseases. Globalization, GMOs and biofuel production pose severe threats to food market control and food security. Our society needs to meet a great challenge; that is to secure access to safe food and healthy eating for all. In meeting this challenge the agro-food science community must play a leading role. Agriculturists, food scientists, food engineers, nutritionists and communicators could all co-operate to contribute in systematic and effective ways towards meeting this humanitarian target. Supporting the IUFoST taskforce on Food Security could be a reasonable approach in exchanging ideas and joining forces to combat hunger and malnutrition-related diseases. A similar approach could be used to fight the global epidemic of obesity.

\section{Acknowledgements}

Part of this paper was presented at the Carlo Lerici Memorial Conference, Bertinoro, Italy, March 18-19, 2010. The author is grateful to the Conference organizers for generously offering an invitation together with financial support.

\section{References}

FAO. (2009). 1.02 billion people hungry. one sixth of humanity undernourished - more than ever before. Retrieved from Retrieved 27. 11.2011fromwww.fao.org/news/story/en/ item/20568/icode/

FAO. (2002). The state of food insecurity in the world 2002. Retrieved from Retrieved 27. 11. 2011fromwww . fao . org / docrep / 005 / Y7352e/y7352e00.HTM

IASO. (2010). The global epidemic. Retrieved from Retrieved27 . 11 . 2011fromhttp : / / www . iaso . org / iotf / obesity / obesitytheglobalepidemic/

Konefal, J., Mascarenhas, M., \& Hatanaka, M. (2005). Governance in the global agro-food system: backlighting the role of transnational supermarket chains. Agriculture and Human Values, 22(3), 291-302. doi:10 . 1007/s10460-005-6046-0

Koutsoumanis, K., Pavlis, A., Nychas, G.-J. E., \& Xanthiakos, K. (2010). Probabilistic model for listeria monocytogenes growth during distribution, retail storage, and domestic storage of pasteurized milk. Applied and Environmental Microbiology, 76(7), 2181-2191.

Lang, T., Rayner, G., \& Kaelin, E. (2006). The food industry, diet, physical activity and health: a review of reported commitments and practice of 25 of the worlds largest food companies. report to world health organisation. London: Centre for Food Policy, City University. 
Lawrence, F. (2006). World's top 25 food firms 'pathetic' in combating unhealthy diets. The Guardian. Retrieved from www. guardian.co.uk/food/Story/0,,1746169,00. html

Ortiz-Hernandez, L., Nayeli Acosta-Gutierrez, M. E., Nunez-Perez, A., Peralta-Fonseca, N., \& Ruiz-Gomez, Y. (2007). Food insecurity and obesity are positively associated in mexico city schoolchildren. Revista De Investigacion Clinica, 59(1), 32-41.

Sassenrath, G. F., Heilman, P., Lusche, E., Bennett, G. L., Fitzgerald, G., Klesius, P., ... Zimba, P. V. (2008). Technology, complexity and change in agricultural production systems. Renewable Agriculture and Food Systems, 23(4), 285-295.

Simopoulos, A. P. (1985). The health implications of overweight and obesity. Nutrition Reviews, 43(2), 33-40.

White, B., \& Dasgupta, A. (2010). Agrofuels capitalism: a view from political economy. Journal of Peasant Studies, 37(4), PII 927236478. doi:10. $1080 / 03066150.2010$. 512449 